\title{
Índice do número 22
}

Artigos

1. Sobre a colocação histórica dos clíticos em romeno e em português

Simona Ailienii (Universidade “Alexandru Ioan Cuza” de Iași (SMELPS/IF))

2. The Dawn of Maria Genta: Metrics, Textual Criticism and Interpretation in Roi

Paez de Ribela B 1439 / V 1049

Rip Cohen (The John Hopkins University)

3. A linguaxe non binaria: unha proposta a partir da tradución

Carla Míguez Bóveda (Universidade de Vigo)

4. Os termos para as cores en galego: unha selva por explorar

Paula Teixeira Moláns (University of Glasgow)

5. Uma tríade indissolúvel: neofalantismo, identidade e qualidade de língua

Vitor Vaqueiro (Investigador independente)

Recensións

$137-162$

1. Fernando Venâncio, Assim nasceu uma língua, Lisboa, Guerra \& Paz, 2019,

311 páxinas.

Serxio Couso Núñez

$139-144$

2. Sverker Johansson, En busca del origen del lenguaje, Barcelona, Ariel, 2021, 425 páxinas.

Serxio Couso Núñez

3. Julio I. González Montañés, Anxo Angueira e Ramón Mariño Paz (eds.),

Entremés galego ao feliz e real parto da nosa raína, Santiago de Compostela, Edicións Laiovento, 2019, 186 páxinas.

Yolanda Gallardo Silva

$151-155$

4. Francisco Dubert-García, Vítor Míguez e Xulio Sousa (eds.), Variedades lingüísticas en contacto na Península Ibérica, Santiago de Compostela, Consello da Cultura Galega, 2020, 220 páxinas.

Noemi García Rodríguez

Contido dos números anteriores da Revista Galega de Filoloxía

$163-173$ 
Contents issue 22

1. On the historical order of clitics in Romanian and Portuguese

Simona Ailienii (Universidade "Alexandru Ioan Cuza” de Iași (SMELPS/IF))

2. A Alva da Maria Genta: Métrica, Crítica textual, e Interpretação em Roi Paez de Ribela B 1439 / V 1049

Rip Cohen (The John Hopkins University)

3 . Non-binary language: a proposal based on translation

Carla Míguez Bóveda (Universidade de Vigo)

4. The colour terms in Galician: a jungle to be explored

Paula Teixeira Moláns (University of Glasgow)

89-106

5. An indissoluble triad: New speakers, identity and language quality

Vitor Vaqueiro (Investigador independente)

$107-136$ 